\title{
Solitary cecal diverticulitis, a rare cause of right lower quadrant pain: Four cases
}

\author{
Adem Yuksel, ${ }^{1}$ Osman Civil, ${ }^{2}$ Muhammed Kadri Colakoglu, ${ }^{3}$ Fatih Sumer,${ }^{4}$ Ahmet Tugrul Eruyar ${ }^{5}$ \\ ${ }^{1}$ Department of Gastrointestinal Surgery, Kocaeli Derince Training and Research Hospital, Kocaeli, Turkey \\ 2Department of General Surgery, Kocaeli Derince Training and Research Hospital, Kocaeli, Turkey \\ ${ }^{3}$ Department of Gastrointestinal Surgery, Recep Tayyip Erdogan University, Rize, Turkey \\ ${ }^{4}$ Department of Gastrointestinal Surgery, Inonu University, Malatya, Turkey \\ ${ }^{5}$ Department of Pathology, Kocaeli Derince Training and Research Hospital, Kocaeli, Turkey
}

\begin{abstract}
Solitary cecal diverticulitis is a rare clinical condition. Like diverticulitis in other segments of the colon, it requires immediate surgical intervention if it is causing complications. Solitary cecal diverticulitis may be misdiagnosed as acute appendicitis, since it causes right lower quadrant pain, or as a cecal tumor or inflammatory bowel disease, due to an intraoperative appearance resembling an inflammatory mass. Four patients with solitary cecum diverticulitis presenting with acute right lower quadrant pain are discussed in this report. Three patients underwent surgery with a preliminary diagnosis of acute appendicitis or cecal tumor, and 1 patient was diagnosed with cecal diverticulitis and treated medically. The treatment approach may change depending on a preoperative or intraoperative diagnosis of cecal diverticulitis. Therefore, in areas where this disease is uncommon, cecum diverticulitis should not be forgotten in the differential diagnosis of acute right lower quadrant pain or inflammatory bowel mass.
\end{abstract}

Keywords: Acute abdominal pain; acute appendicitis; cecal diverticulitis.

Cite this article as: Yuksel A., Civil O., Colakoglu M. K., Sumer F., Eruyar A. T. Solitary cecal diverticulitis, a rare cause of right lower quadrant pain: Four cases. North Clin Istanb 2018;5(2):148-152.

A cute abdominal pain is one of the most frequent causes of emergency service applications in adults, It constitutes $4-6.5 \%$ of all emergency service applications [1]. Acute diverticulitis is also one of the most frequent causes of acute abdominal pain. Eighty-85\% of the patients with colonic diverticular disease lead an asymptomatic course, while in nearly $4-15 \%$ of the patients episodes of acute diverticulitis are seen [2].

In Western countries, cecal diverticulas are rarely seen clinical entities among patients with colonic diverticula. It has been reported that cecal diverticula comprise 3.6 $\%$ of all colonic diverticula [3]. Therefore in Western societies cecal diverticulitis are rarely encountered clinical entities. Ninety-nine percent of the patients with cecal diverticulitis present with right lower quadrant pain.
Clinically, they often imitate acute appendicitis which requires emergency surgery [3].

In this study we aimed to present, and discuss three cases with solitary cecal diverticulitis who were treated with the initial diagnosis of acute appendicitis, and a patient who was diagnosed as cecal diverticulitis based on examinations performed to find out the etiology of the right lower quadrant pain, and treated medically in the light of the literature information.

\section{CASE REPORT}

Case 1- A 18-year-old male patient applied to the emergency service with right lower quadrant pain persisting for three days. The patient had not complaints of Received: March 03, 2017 Accepted: July 31, 2017 Online: March 15, 2018

Correspondence: Dr. Adem YUKSEL. Department of Gastrointestinal Surgery, Kocaeli Derince Training and Research Hospital, Kocaeli, Turkey.

Phone: +902623178000 e-mail: drademyuksel@gmail.com

(c) Copyright 2018 by Istanbul Provincial Directorate of Health - Available online at www.northclinist.com 
nausea, vomiting, diarrhea, and loss of appetite. Physical examination revealed tenderness on the right lower abdominal quadrant, rebound tenderness, and abdominal guarding. White blood cell count (WBC) $\left(10.2 \times 10^{6} /\right.$ $\left.\mathrm{mm}^{3}\right)$, and C-reactive protein (CRP) $(40.7 \mathrm{mg} / \mathrm{dl})$ were measured as indicated. The diameter of the appendix was $6 \mathrm{~mm}$. The patient was urgently operated in consideration of his clinical findings. Through Mc Burney incision, abdominal cavity was entered. Abdominal exploration revealed minimal free fluid in the intraabdominal cavity, and an inflammatory mass covered with fibrinous material nearly $1 \mathrm{~cm}$ distal to the ileocecal region, and occupying nearly an area of a diameter of $3 \mathrm{~cm}$ on the anterior surface of the cecum (Fig. 1). Appendix had a normal appearance. Inflammatory intestinal disease was presumed, and through the same incision ileocecal resection was performed. Histopathological examination of the specimen was reported as cecal diverticulitis next to ileocecal valve whose opening occluded with a fecal plug. Patient's health state was stable during postoperative follow-up period. The patient was discharged on postoperative 5. day. Any pathology was not observed during colonoscopic examination performed at 3. postoperative month.

Case 2- A 34-year-old female patient applied to emergency service with complaints of right lower quadrant, and suprapubic pain persisting for 4 days. Physical examination revealed the presence of right lower quadrant tenderness, rebound and abdominal guarding. White blood cell counts (WBC) $\left(11.2 \times 10^{6} / \mathrm{mm}^{3}\right)$, and CRP (20.3 mg/dl) were measured as indicated. As for differential diagnosis the patient was evaluated using intravenous, and oral contrast-enhanced abdominal to-

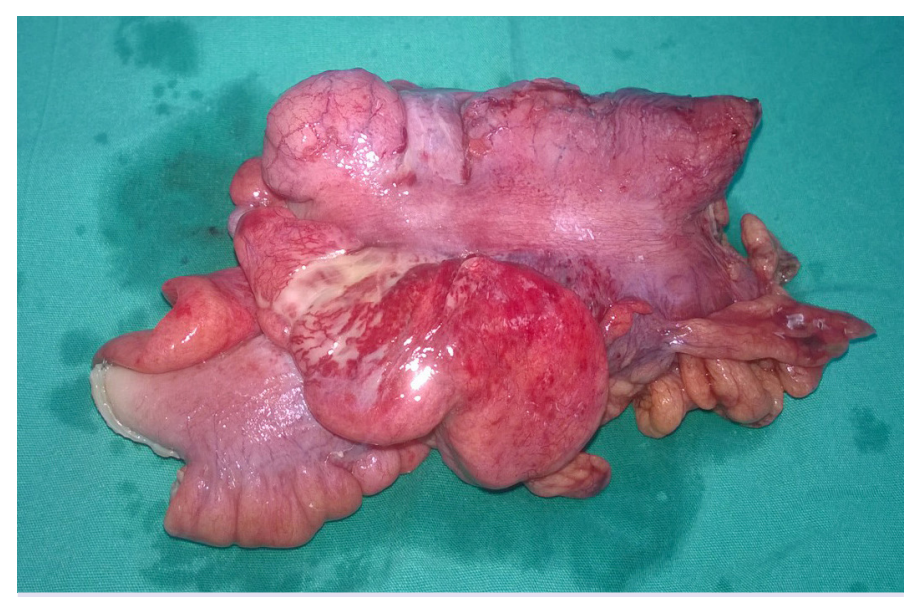

FIGURE1. Diverticulitis on the anterior aspect of cecum (Ileocecal Resection). mography (CT). On CT free fluid in pelvis, right lower quadrant, Morrison pouch, contamination of the right lower quadrant mesentery, and heterogenous contrast uptake on the wall of the cecum were detected (Fig. 2). The patient was evaluated as case with perforated appendicitis based on radiological examination, and clinical findings. Through Mc Burney incision the abdominal cavity was entered. Free serous fluid in the intraabdominal cavity, and mass lesion on the anterior surface of the cecum were detected. Then midline laparotomy was performed. Since maligancy could not be discarded, lymphadenectomy together with right hemicolectomy was performed. The health state of the patient led a stable course, and she discharged at 6 . postoperative day. Histopathological examination revealed the presence of pericolic abscess formation, inflammatory granulation tissue, and cecal diverticulitis (Fig. 3). On colonoscopy performed at 4. postoperative month any pathology was not observed.

Case 3- A 21-year-old female patient consulted emergency room with complaint of right lower quadrant pain persisting for 3 days. Physical examination revealed a generalized abdominal tenderness, rebound, and guarding especially prominent on the right lower abdominal quadrant. WBC $\left(11.2 \times 10^{6} / \mathrm{mm}^{3}\right)$ and C-reactive protein (CRP) $(44.2 \mathrm{mg} / \mathrm{dl})$ levels were as indicated. As for differential diagnosis the patient was evaluated using intravenous contrast-enhanced abdominal tomography (CT). On CT, cecal wall consolidation along a 7-cm-segment on the pericecal area which extended up to ileocecal valve, and ascending colon, and paracecal free fluid was observed. The patient was operated with the diagnosis of perforated appendicitis. Through Mc Burney inci-

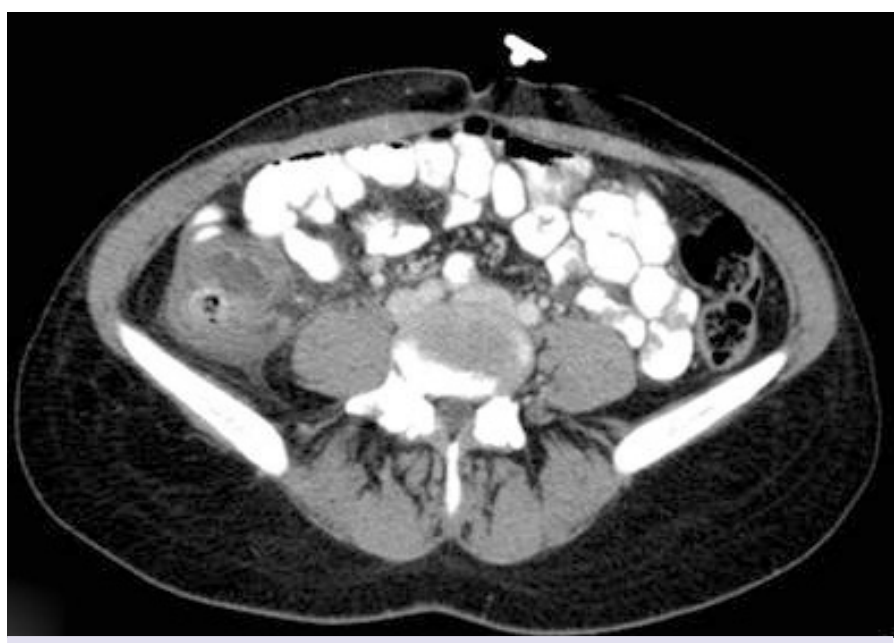

FIGURE 2. Appearance of cecal diverticulitis on CT. 
sion intraabdominal cavity was entered. Intraabdominal purulent fluid, and an inflammatory mass nearly $4 \mathrm{~cm}$ in diameter on the anterior surface of the cecum, and in the close vicinity of ileocecal valve were seen. Since malignancy could not be ruled out, we performed lymphadenectomy together with right hemicolectomy (Fig. 4). The patient was discharged on postoperative 5. day. On histopathological examination pericolic abscess formation, inflammatory granulation tissue, and cecal diverticulitis were detected.

Case 4- A 22-year-old male patient applied to emergency polyclinic with complaint of right lower abdominal quadrant pain persisting for 2 days. Physical examination of the patient revealed right lower abdominal quadrant tenderness, rebound, and guarding. WBC $\left(11.0 \times 10^{6} /\right.$ $\mathrm{mm}^{3}$ ), and C-reactive (CRP $441.0 \mathrm{mg} / \mathrm{dl}$ ) values were measured as indicated. On contrast-enhanced abdominal CT, signs consistent with diverticulitis on the anterior surface of the cecum were detected (Fig. 4). The patient received antibiotherapy (2nd generation cephalosporin). The patient's complaint of abdominal pain regressed after treatment. His laboratory values dropped within normal ranges. The patient was discharged with recommendations. During first postoperative follow-up of the patient any medical problem was not detected.

\section{DISCUSSION}

Diverticulitis is an important clinical condition which effects $4-15 \%$ of the patients with colonic diverticular disease [2]. In Western countries, diverticula mostly settle on the left colon. Therefore, right colonic diverticula

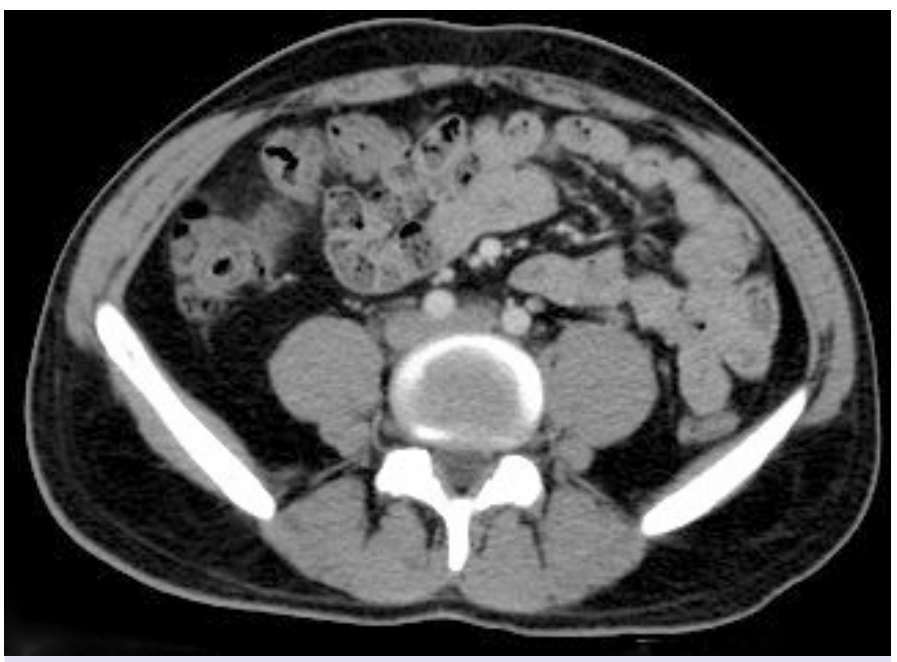

FIGURE 3. Appearance of cecal diverticulitis on CT. consist only $1.5 \%$ of the cases. Right colonic diverticula may be single or multiple, and settle on appendix, cecum or ascending colon Solitary cecal diverticulum is a real congenital diverticulum generally involving all layers of the bowels. Nearly $80 \%$ of cecal diverticula generally settle on the anterior surface of the cecum on an area between $1 \mathrm{~cm}$ proximal, and $2 \mathrm{~cm}$ distal to ileocecal valve [5]. Also in our cases, solitary diverticula on the anterior surface of the cecum nearly $1-2 \mathrm{~cm}$ distal to the ileocecal valve was found.

Cecal diverticulitis cause right lower quadrant pain in $99 \%$ of the patients, and in the differential diagnosis it may be confused with diseases which cause right lower quadrant pain including especially acute appendicitis, inflammatory bowel disease, and cancer of cecum. As an important issue, cecal diverticulitis should be differentiated from diseases which require surgical intervention as acute appendicitis, and cancer of cecum. Indeed, acute diverticulitis which did not lead to complications as abscess, fistula, obstruction or perforation may be treated using medical methods [6].

In some studies, it has been reported that different from acute appendicitis, relatively more prolonged right lower abdominal quadrant pain, but less frequent complaints of nausea, and vomiting, presence of diarrhea, WBC counts just over upper limit of normal with lower percentage of polymorphonuclear leukocytes, but higher percentage of lymphocytes in differential counts may aid in the establishment of differential diagnosis of di-

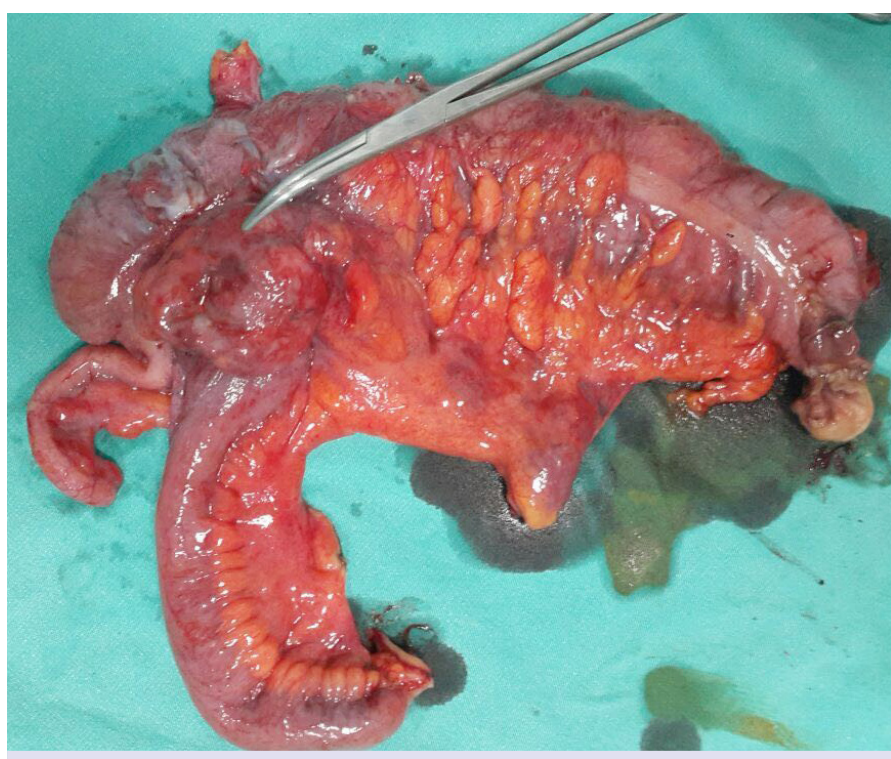

FIGURE 4. Diverticulitis on the anterior aspect of cecum (Right Hemicolectomy). 
verticulitis [7-9]. However some investigators reported that this clinical discrimination could not be made easily based only on clinical, and laboratory findings, and 75 $\%$ of the patients received the preoperative diagnosis of acute appendicitis, while only $6 \%$ of the patients received the preoperative diagnosis of cecal diverticulitis [4].

Conventional radiological examination methods do not geerally aid in the establishment of diagnosis of cecal diverticulitis. Ultrasound is a widely used diagnostic radiological examination in patients presented with acute abdominal pain. On ultrasonograms detection of hypo or anechoic formations protruding from colonic wall may aid in making diagnosis of diverticulitis. In a study, Chou et al. reported sensitivity, and specificity as 91.3, and 99.8\%, respectively [10]. However, in contrast with this study, much lower rates of accurate diagnosis as low as $22.6 \%$ were also reported [11]. Rates of accurate ultrasonographic diagnosis may be adversely affected by some factors including small size of the diverticulum, obesity, tenderness on the right lower abdominal quadrant, and presence of intestinal gasses which lead to suboptimal US examination. Besides, US is an operator- dependent examination, and lack of experience in the assessment, and interpretation of the regions where cecal diverticulum is rarely seen may decrease diagnostic value of the ultrasonographic examination. Signs of diverticulitis noted during computed tomography include thickening of the cecal wall, focal pericecal inflammation extending to the adjacent fascia, diverticulitis-related abscess, extraluminal air, and mass. The sensitivity, and specificity of computed tomography in the differential diagnosis between acute appendicitis, and cecal diverticulum has been reported as $98 \%$ in various studies $[3,10]$. However, in the presence of inflammation, CT could not reportedly differentiate between cecal diverticulitis, and cecal cancer in $10 \%$ of the cases [16]. In our case that was evaluated preoperatively using US, small diameter of the diverticulum, and its rarety might decrease diagnostic accuracy of US. In 2 out of 3 patients that were evaluated using computed tomography, we thought of perforated acute appendicitis because of diffuse inflammation found in the right lower abdominal quadrant. In consideration of clinical findings of the patient, surgical treatment was decided.

The most important point in the treatment of cecal diverticulitis is establishment of accurate preoperative diagnosis. Some literature studies have demonstrated that the patients diagnosed as cecal diverticulitis during preoperative period may be treated using conservative approaches (IV antibiotherapy) [7, 12]. However it has been reported that during preoperative period, only $6 \%$ of the patients could receive the diagnosis of cecal diverticulitis, and $75 \%$ of the patients had been operated with the diagnosis of acute appendicitis, while $65-84 \%$ of the surgically treated patients could receive intraoperative diagnosis of cecal diverticulitis $[4,12]$. Therefore, a standardized surgical approach to cecal diverticulitis does not exist. In some studies, conservative surgical approaches (appendectomy, drainage, diverticulectomy etc.) have been recommended, and disease recurrence of $15 \%$ has been reported. On the contrary, some studies have indicated that since the presence of malignancy could not be ruled out, and disease recurrence rate of $40 \%$ is seen in the treatment of cecal diverticulitis mostly diagnosed intraoperatively, resection of all visible diseased areas are advisable (ie. right hemicolectomy) $[4,12,15]$. In conclusion, based on the extent of inflammation, experience of the surgeon, and intraoperative diagnosis, different procedures as appendectomy combined with drainage, diverticulectomy, ileocecal resection or right hemicolectomy may be applied using conventional or laparoscopic techniques [4, 12-15]. In one of our cases, limited resection (ileocecal resection) was performed with suggestive intraoperative diagnosis of inflammatory bowel disease, and in other two cases intraoperative malignancy could not be discarded so lymphadenectomy together with right hemicolectomy was performed.

In the management of cecal diverticulitis accurate pre, and postoperative diagnosis should be made. Especially in regions where this disease is rarely seen, cecal diverticulitis should not be overlooked in the differential diagnosis of acute right lower quadrant pain or inflammatory cecal mass.

Informed Consent: Written informed consent was obtained from the patient who participated in this study.

Conflict of Interest: No conflict of interest was declared by the authors.

Financial Disclosure: The authors declared that this study has received no financial support.

Authorship contributions: Concept - A.Y., O.C.; Design - A.Y., F.S.; Supervision - M.K.C.; Materials - A.Y., O.C.; Data collection \&/or processing - A.Y., A.T.E.; Analysis and/or interpretation - A.Y., O.C., A.T.E.; Writing - A.Y.; Critical review - F.S.

\section{REFERENCES}

1. Hastings RS, Powers RD. Abdominal pain in the ED: a 35 year retrospective. Am J Emerg Med 2011;29:711-6. [CrossRef] 
2. Shahedi K, Fuller G, Bolus R, Cohen E, Vu M, Shah R, et al. Long-term risk of acute diverticulitis among patients with incidental diverticulosis found during colonoscopy. Clin Gastroenterol Hepatol 2013;11:1609-13.

3. Sardi A, Gokli A, Singer JA. Diverticular disease of the cecum and ascending colon. A review of 881 cases. Am Surg 1987;53:41-5.

4. Graham SM, Ballantyne GH. Cecal diverticulitis. A review of the American experience. Dis Colon Rectum 1987;30:821-6. [CrossRef]

5. Lauridsen J, Ross FP. Acute diverticulitis of the cecum; a report of four cases and review of one hundred fifty-three surgical cases. AMA Arch Surg 1952;64:320-30. [CrossRef]

6. Wada M, Kikuchi Y, Doy M. Uncomplicated acute diverticulitis of the cecum and ascending colon: sonographic findings in 18 patients. AJR Am J Roentgenol 1990;155:283-7. [CrossRef]

7. Cristaudo A, Pillay P, Naidu S. Caecal diverticulitis: Presentation and management. Ann Med Surg (Lond) 2015;4:72-5. [CrossRef]

8. Cho HJ, Cho SY, Oh JH. Clinical Analysis of Right Colonic Diverticulitis That was Operated under the Impression of Acute Appendicitis. J Korean Soc Coloproctol 2000;16:18-24.

9. Shin JH, Son BH, Kim H. Clinically distinguishing between appendicitis and right-sided colonic diverticulitis at initial presentation. Yonsei Med J 2007;48:511-6. [CrossRef]
10. Chou YH, Chiou HJ, Tiu CM, Chen JD, Hsu CC, Lee CH, et al. Sonography of acute right side colonic diverticulitis. Am J Surg 2001;181:122-7. [CrossRef]

11. Lee IK, Kim SH, Lee YS, Kim HJ, Lee SK, Kang WK, et al. Diverticulitis of the right colon: tips for preoperative diagnosis and treatment strategy. J Korean Soc Coloproctol 2007;23:223-31. [CrossRef]

12. Lane JS, Sarkar R, Schmit PJ, Chandler CF, Thompson JE Jr. Surgical approach to cecal diverticulitis. J Am Coll Surg 1999;188:629-34.

13. Altun H, Mantoglu B, Okuducu M, Onur E, Baskent A, Karip AB, et al. Therapy of solitary cecal diverticulitis in a young patient with laparoscopic right hemicolectomy. Surg Laparosc Endosc Percutan Tech 2011;21:e176-8. [CrossRef]

14. Hot S, Eğin S, Gökçek B, Yeşiltaş M, Alemdar A, Akan A, et al. Solitary caecum diverticulitis mimicking acute appendicitis. Ulus Travma Acil Cerrahi Derg 2015;21:520-3.

15. Fang JF, Chen RJ, Lin BC, Hsu YB, Kao JL, Chen MF. Aggressive resection is indicated for cecal diverticulitis. Am J Surg 2003;185:135-40.

16. Jang HJ, Lim HK, Lee SJ, Lee WJ, Kim EY, Kim SH. Acute diverticulitis of the cecum and ascending colon: the value of thin-section helical CT findings in excluding colonic carcinoma. AJR Am J Roentgenol 2000;174:1397-402. [CrossRef] 